\title{
Regulation and Control in Hierarchical Organizations
}

\section{Nancy C. Morse, Everett Reimer, and Arnold S. Tannenbaum1}

The study of social organization has passed the stage of fact gathering, undirected by hypothesis. We do not, however, have many welldefined variables to serve as the terms of hypotheses. The discovery of variables which have general application, subsume important social phenomena, and are capable of operational definition, is therefore im. portant. We will describe our attempts to define two such variables in the area of organizational regulation and control.

There have been other attempts which we have tried to take into account and from which we have profited. The dominance-submission continuum developed in the study of personality may be regarded as a regulation and control variable, important particularly in two-person interrelationships. The comparative study of "democratic", "authoritarian", and "laissez-faire" groups by Lewin, Lippitt, and White has emphasized the control behavior of the leader as an important variable in the face-to-face group. Most recently James Worthy ${ }^{2}$ has suggested the "flatness" of an hierarchic structure and the presumably related decentralization of decision-making.

The concept of organizational regulation and control is so closely intertwined with the concept of collective organization that hoth require some preliminary discussion.

\section{A General Description of Organizations}

An organization is composed of individuals (and objects) interacting in predictable ways. These inter-relationships are functional, that is, they result in the production or exchange of some object or behavior required or desired by at least some of the individuals involved. There are certain of these "social products" which are intermediate or means products for the organization and others which are end products. Any organization may be characterized or described in terms of its specialized "social end products", whether they be concrete "goods" or less tangible "services".

\footnotetext{
1The authors would like to express their indebtedness to Dr. Floyd H. Allport. The analysis following is in keeping with a more general theory of the structure of events involved in behavior and collective action which is being prepared for publication by Dr. Allport.

2Worthy, James C., "Factors Influencing Employee Morale," Harvard Business Review, Vol. 28, No. i. January 1950 .
} 
These "social end products" may be available for use by individuals or groups outside the organization or they may be available only for the members of the organization. A social service organization which supplies medical facilities to the community would fall in the first class, while a social club set up for the entertainment of its members would fall in the second. In either case the processes which result in the "social end product" may be regarded as the "core" of the organization, since their failure would lead most swiftly and surely to its dissolution. These core processes are the essential functions of the organization. But for the establishment and maintenance of these "core" processes, other supplementary ones are required.

The supplementary processes can be divided into two categories; those which supply continuing standard requirements, e.g. acquiring members, materials, etc. and those which establish, maintain, or change the form or character of the organizational relationships involved. The latter are specifically processes of control and regulation. They determine the what, how, when, and where of organizational relationships. In industrial organizations, for example, the control processes include decisions on what work processes are to be used, how employees will be paid, when employees will come to work, and where new employees will be placed.

\section{Dimensions of Regulation and Control}

There are two aspects of the regulation and control processes of organizations which suggested themselves as subject to quantification and experimental variation: "degree of control" and "location of control". By "degree of control" we mean the degree to which the behavior of individual members is determined by their organizational relationships. By "location of regulation and control" we mean the organizational distribution of the control processes.

"Degree of control". depends both upon the number of areas of the individual's behavior which are determined by organizational membership and the degree to which each area is determined. Organizational membership may control a large or small part of an individual's behavior. It may control his economic, political, social, or religious behavior, or parts of each to a different degree. Employment in a factory will control a worker's hours, the type of work he does, and his informal behavior, but to different degrees. While the number of areas of behavior controlled by a given organizational membership is an important aspect of "degree of control" in comparing different organizations, we have not dealt with this aspect of "degree of control". We have been concerned, instead, with the amount of control over given areas, an aspect of "degree of control" which is more likely to vary within an organization. 
"The location of control", or distribution of the control processes within an organization, can be expressed in terms of the hierarchical axis of the organization. Where in the hierarchical pyramid are the regulation and control processes situated? This question is of course a crude one. In most instances control is not located exclusively at any one level in an hierarchy. A better description of location of control is the degree to which control is located at certain levels relative to others.

\section{The Measurement of the Two Control Variables}

The first attempt to measure and manipulate aspects of regulation and control, as here defined, was made recently in an experiment with clerical workers in a large company. ${ }^{3}$ Specifically the project called for the manipulation of the location of regulation and control processes with respect to the hierarchical axis of the company and for the measurement of both degree and location of control before, after, and during the manipulation.

In order to measure location of control and degree of control, it was first necessary to identify the referent of the control processes the types of organized inter-relationships operating in the company. It was possible to divide most of the social structures in which individuals operate into organizational systems identified in terms of "social product". These systems could be quite unambiguously defined. Thus the "work system" included all of the actual clerical processes directly involved in producing the end products of the work units. Directly related, but separable, were the "work assignment system" and the "work measurement system". Many supportive systems were also identified, such as the "pay system", the "vacation system", the "promotion system", etc. Twenty. eight systems were selected. In addition, a group of less formalized interrelationships, such as friendships, etc., were simply classified and described in terms of social product.

The control processes themselves had to be defined at a level of specificity which would avoid ambiguous reference as well as an unmanageable number of measures. A classification of the control processes was made in terms of those which establish, carry out, and secure conformity to each type of social structure involved. The decision-making processes involved in establishing, amending, and changing the systems were labeled as legislative. The behaviors involved in carrying out "legislative decisions", i.e., in making and keeping the systems operative on a day to day basis were described as administrative. The punishment of nonconformity was called the sanctions process.

aFor a more detailed description of the experimental design see Nancy Morse, "An Experimental Study in an Industrial Organization", Groups, Leadersbip and Men, edited by Harold Guetzkow (Pittsburgh: Carnegie Press 1951); see also Nancy Morse, Everett Reimer, and Arnold Tannenbaum, "The Experimental Change of a Major Organizational Variable" to be published slortly by the Survey Research Center. 
This classification of regulation and control proved useful in the design of specific measures. The three types of processes may be differently distributed within an organization. Commonly, however, the same in. dividuals are involved in each type of process; processes of each type are situationally intermingled and borderline instances are not easily classified. Therefore as an explanatory concept, this classification of control processes may have more limited usefulness than the popularity of the terms legislative, administrative and sanction would suggest.

The location of legislative, administrative, and sanction control for each system was determined by a series of six questions. The questions for each system were preceded by a description of the purpose and major parts of the system. The six questions asked of the clerks for the "work system" were:

\section{Legislative}

To what degree do company officers or any employees of a higher rank than yours decide how the work system is set up and decide the policies, procedures, or methods of the work system?

not at to a slight
all $\quad \begin{gathered}\text { to some } \\ \text { degree }\end{gathered}$ to a fairly $\begin{gathered}\text { to a very } \\ \text { high degree }\end{gathered}$

To what degree do you and the girls in your section decide how the work system is set up and decide the policies, rules, procedures, or methods of the work system?
not at
to a slight
to some
to a fairly
high degree
to a very
high degree

\section{Administrative}

How often does your supervisor, manager, or other company officet give you instructions, advice, make suggestions, or help you with regard to the work s;stem? never rarely sometimes often always

How often do the girls in your section give advice, make suggestions or generally help each other carry out the rules, and policies in the day to day operation of the work system?

never rarely sometimes often always

Sanctions

If you were to deliberately disregard the established methods, policies, rules or procedures of the work system, how severely would you be reprimanded by your supervisor, manager, or other company officers?
not at
to a slight
to some
to a fairly
to a very
high degree high degree

If you were to deliberately disregard the established methods, policies, rules, or procedures of the work system, how much would the girls in your section disapprove or dislike it?

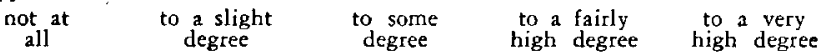

Similar questions were answered by the first and second line super. visors. Each reported the degree to which people at his level or below, and the degree to which people above his level, were controlling and regulating each of the systems. Location of control was thus measured by a series of ratios - control exercised by superiors to control exercised by those on one's own level or subordinates. To obtain the legislative index of the work system, for example, the answers to the first question, converted to numerical scores, were divided by the converted answers to the second question. A general control and regulation index was computed 
by obtaining an average of the legislative index, the administrative index and the sanction index for each system. In order to characterize an entire organization in terms of location of control as measured here, it would be necessary to ask similar questions of all levels of the organization. Since the experiment did not extend to levels above the second-line supervisor, the higher levels were not included in the measurement.

The same measuring instrument also provides data on the degree of total control. The degree of control of the work system for non-supervisory employees, for example, is the summation of control by superiors and by individuals at their own level. A low degree of control score for a system would mean that the system is controlled only slightly by superiors and peers. It would mean that each individual was free to operate in it as he saw fit. Such a situation could be described as laissez-faire.

This measurement device has numerous advantages and some dif. ficulties. It provides a detailed picture of regulation and control in the organization. It relies, however, on the report of those directly involved, many of whom have never thought in these terms before. The questionnaire we used was very long and repetitious. Yet despite these and various other problems the results obtained using this approach corresponded closely to what we would have predicted from our direct knowledge of location of control in the company. Observational and other objective methods for obtaining location and degree of control were included in the study for comparison with the questionnaire material. In future studies it should be possible to reduce the number of systems and of less formal social structures covered in the questionnaire.

\section{The Manipulation of Location of Control}

Several difficult problems were involved in manipulating the location of control variable. The experimental plan required increasing the ratio of upper to lower level control in one group and decreasing it in another comparable group. The basic problems were: (1) to avoid manipulations in either group which were not manipulations of location of control, (2) to avoid a shift in degree of control, (3) to avoid differential secondary effects on our dependent variables which would mask the primary effects. These problems were met in various ways.

The basic manipulations used in the experiment were, in and of themselves, simply immediate shifts in the variable. It was possible to shift control in one direction by building new control systems at upper hierarchical levels, in the other by delegation. The close relationship between the experimental operations and the variable reduced the likelihood that extraneous variables were also being manipulated. It was possible, however, that differential values might be attached to the experimental changes which were independent of the changes themselves. 
For example, delegation might be viewed as a reward for past performance or be interpreted as a signal for future company policy. It was easy to find very substantial bodies of tradition, both in the company and in our national culture, to rationalize changes in either direction, and thus minimize this problem.

Shifting radically the location of regulation and control without provision for the building and acceptance of new control systems would have brought about a drop in degree of control. To avoid this in the group where location of control was shifted downwards, training programs of the supervisory personnel were undertaken. In these training sessions the supervisors planned out their new roles and agreed on certain requirements for delegation to the non-supervisory employees. Delegation to the employees was to work-groups, not to individual employees. Thus group discussion and consensus decision rather than individual action were required. To avoid a drop in degree of control in the group where location of control was shifted upwards, supervisory training programs were instituted to indicate the part the supervisor had in the total company operation. Furthermore, the introduction of new controls was planned in a way which would reduce the likelihood that supervisors would fail to take responsibility for seeing that the new controls operated effectively.

Our choice of major dependent variables, group productivity and need satisfaction, complicated the problem of secondary effects. Either differential methods changes or changes in privileges could have masked completely the effect of our shifts in location of regulation and control on productivity and need satisfaction. The experimental limitations, designed to avoid this, worked well but at the price of limiting the amount of change we could bring about in our variable.

In addition to the three difficulties we have discussed, a final and . major one lay in the fact that the location of specific regulation and control processes was a matter of permanent concern to individuals in the company, outside of the experimental group.

Our experimental design maximized the difficulties of manipulating the hierarchical location of regulation and control processes, primarily by inhibiting a maximum shift. Nevertheless, a significant shift was accomplished. In many other situations the problems of manipulation should prove more easily manageable.

\section{Effects of Location of Control}

The preliminary stage of analysis permits only very limited and tentative generalizations about the effects of shifting regulation and con. trol hierarchically. 
(1) the effect of shifting controls downward seems to result in significantly greater organizational involvement as measured by expressed willingness to expend effort to retain organizational relationships.

(2) it appears that legislative and administrative control processes can be more successfully delegated to groups composed of equal status members than sanction processes.

(3) strong resistances are encountered at many levels in a going organization to an attempt to move the location of control and regulation either up or down hierarchically.

(4) one of the major problems in moving control processes hierarchically downward, without loss of degree of control, is to provide sufficient incentive for energy expenditure in the control processes themselves.

(5) the loss of organizational uniformity which results from moving control processes hierarchically downward appears to cause far fewer and less severe problems than are anticipated by management.

(6) there seems to be no simple one-to-one relationship between level of productivity and shift in location of control.

Further and more explicit findings will certainly result from additional analysis of our experimental data.

\section{Broader Application of the Variables}

The development and use of "degree of control" and "location of regulation and control processes" as both independent and dependent variables would appear to be profitable for the study of a large variety of social structures. Any application of these concepts, especially to whole organizations and complexes of organizations, must, of course, take account of the entire context of the organization or organizational complex. The most general statement of location of regulation and control is in terms of the relative degree of control of the organization or organizational complex by different relevant groups. Thus, in analyzing government in terms of location of control, it would be necessary to ascertain the degree of control: by the rank and file citizens, i.e., by the electorate; by certain groups in the nation such as business leaders, unions, and the military; by certain high level governmental officials; by intermediate governmental officials; and by the rank and file governmental workers. A similar analysis of the location of control for many industrial organizations would include the spelling out of the relative control of stockholders, upper management officials, labor unions, consumers, and governmental groups over the functioning of the organization. Provided, 
however, the organizational context is completely and accurately defined, the concepts of degree and location of regulation and control should prove fruitful for the study, understanding, and management of organizations. General confirmation of our experimental findings, that organizational involvement is related to the amount of control exercised by a given group (in our case the employees), could be of great im. portance, for example, in relation to problems of responsible citizen participation.

From a more theoretical point of view, it appears that the concepts here outlined might provide a groundwork for the integration of concepts and empirical findings in such presently diverse fields as "organizational structure" and "leadership behavior".

The following lines of inquiry and development appear promising:

(1) the effect of variations in location of regulation and control on degree of control. If location is shifted downward in an organization, will there tend to be less control over the individual by virtue of his membership in the organization?

(2) the effect of variations in hierarchical location of control on the degree of control exercised by other groups or individuals with legitimate "interests", e.g . customers, unions, political parties, stockholders.

(3) study of the relationships between various forms of "social power" and the variables here outlined. Location of control and regulation describes the present functioning of the control and regulation processes. "Social power" may be the ability to hold this location or change it.

(4) adaptation of the present measuring instruments for use in administrative analysis.

(5) the empirical study of the variables here discussed with a variety of other variables in both independent and dependent relation.

(6) the development of alternative methods (preferably objective) of measuring both degree and location of regulation and control.

(7) fuller theoretical exploration of the relation between regulation and control processes, other aspects of organization and the control of individual behavior. What, for example, are the roles of religion, traditions, mores, systems of ethics and logic in the control of individual behavior?

(8) the development of the location of control variable for use in describing total organizations and organizational complexes. 